\title{
Management of Peg-Shaped Lateral with New Minimal Invasive Restorative Technique - Componeer: A Case Report
}

\author{
Neelam Mittal, Anoop Mohandas \\ Department of Conservative Dentistry and Endodontics, Faculty of Dental Sciences, Ims-Bhu, Varanasi - 221 005, Uttar Pradesh, \\ India
}

Email for correspondence: dr.neelammittal@gmail.com

\begin{abstract}
A patient's performance in the society can be often determined by smile, which is his ability to express a range of emotions with the structure and movement of the teeth and lips. The increasing demands for esthetics and recent advances in esthetic dentistry have led to the development of newer materials and techniques with minimal invasion and better natural appearance. Componeer system developed by Coltene, Switzerland, consists of thin prepolymerized hybrid composite shells, several shades of a direct hybrid composite resin, an etch and rinse adhesive system, and restorative accessories including finishing points and disks. This system is minimally invasive one used to restore function and esthetics in one office visit. The present paper presents an esthetic correction of peg-shaped laterals with componeer system.
\end{abstract}

Key words: Componeers, minimal invasive, peg-shaped lateral

\section{INTRODUCTION}

In the recent decades of marketing, everybody wants a perfect personality as well as a perfect smile. Not only young people but elderly people also are now concerned about health and look of their teeth if they are different and do not conform to the norms of a beautiful smile. Peg-shaped laterals are quite common and may hamper patient confidence because of their small size and shape compared to other anterior teeth. A peg lateral is defined as "an undersized, tapered, maxillary lateral incisor" that may be associated with other dental anomalies such as canine transposition and over retained deciduous teeth. ${ }^{[1]}$ Management of peg laterals considers factors such as patient's expectations

\begin{tabular}{|l|l|}
\hline Quick Response Code & Article Info: \\
\hline doi: 10.5866/2018.10.10053 \\
\hline $\begin{array}{l}\text { Received: } 28-12-2017 \\
\text { Revised: } 18-01-2018 \\
\text { Accepted: } 28-01-2018 \\
\text { Available Online: } 15-04-2018,2018 \text { (www. } \\
\text { nacd.in)@ NAD, } 2018 \text { - All rights reserved }\end{array}$ \\
\hline
\end{tabular}

and experience of the practitioner. The selection of treatment type is based on functional and esthetic requirements, need for extractions, the position of canines, and the potential for coordinating restorative and orthodontic treatment. ${ }^{[2]}$ Treatment options include the following: (1) Extraction of the lateral followed by orthodontic movement of canine and its recontouring, (2) extraction and replacement with single tooth implant-supported restoration or a fixed partial denture, and (3) direct and indirect restoration of the peg-shaped laterals to develop normal tooth morphology after orthodontic alignment. ${ }^{[3]}$ The restorative techniques include direct composite restorations, porcelain laminate veneers, metal-ceramic restorations, and all-ceramic crowns as well as minimally invasive direct resin composite bonding veneers. ${ }^{[4]}$ The present case report presents the restoration of bilateral peg laterals with componeers after orthodontic alignment.

Componeer is a new concept based on direct veneering technique with composite which is minimal invasive and expanded range of indications that take a new horizon in esthetic dentistry considering economics and quality. ${ }^{[5]}$ Componeer 
system developed by Coltene, Switzerland, consists of thin pre-polymerized hybrid composite shells, several shades of direct hybrid composite resin, an etch and rinse adhesive system, and restorative accessories including finishing points and disks. This system is a durable esthetic solution in one office visit which is economical as compared to indirect techniques. ${ }^{[6]}$

\section{CASE REPORT}

A 24-year-old male patient was referred to the department of conservative dentistry and endodontics from the department of Orthodontics for the restorative management of bilateral pegshaped lateral incisors. The patient has undergone orthodontic alignment of maxillary teeth and that of mandibular is still going on [Figure 1]. The orthodontic alignment is done in such a way that $2 \mathrm{~mm}$ space is left mesial and distal to the peg laterals to allow esthetic build up. The alignment was symmetrical bilaterally so that they can be built up in the same. The treatment options in front of us were direct composite restoration, ceramic crowns, porcelain veneers, and componeers. Merits and demerits of each procedure are explained to the patient. Composite restoration was discarded because of increased porosity and difficulty in maintaining marginal adaptation. Ceramic crowns were not opted because of extensive reduction. Among porcelain veneer and componeer, componeer was opted in this particular case because of less reduction, no laboratory work, and economical. Debonding of the brackets was done on the same day of restoration to prevent relapse, and on the same day, lingual retainers were placed.

\section{COMPONEER RESTORATION}

The first step was to select the shade and size with the use of Componeer Synergy D6 shade guide

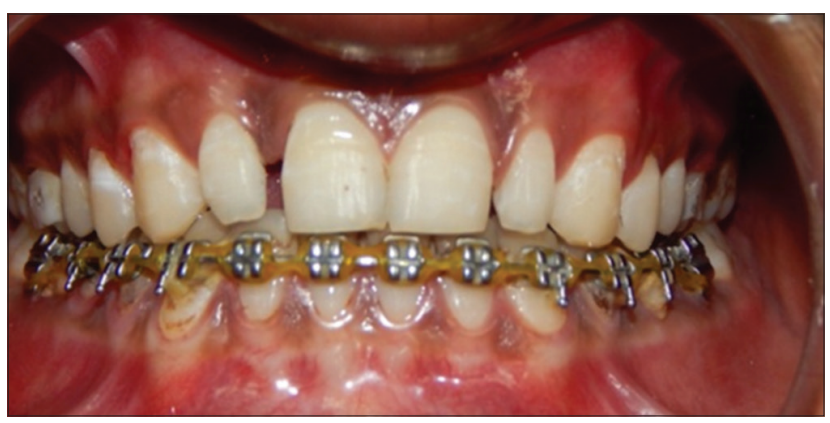

Figure 1: Pre-operative frontal view showing peg-shaped lateral incisors with orthodontic alignment of mandibular teeth still going on
(Coltene) and Contour Guides. The dentin shade selected was A2, and enamel shade was transparent. With the help of contour guides, size "M" (large) was selected. Then, the tooth preparation was done restricting entirely to enamel with uniform reduction in buccal surface using a tapered Cylinder Round End Diamond Bur. The preparation was in such a way that the componeer will lay in the contour of the arch. A \#2 small round bur is used to delimit the cervical margin. Then, the prefabricated componeers were customized with the abrasive discs (Coltene) and tried in. One Coat Bond (Coltene) adhesive is applied to the intaglio surface and left undisturbed without light curing. The preparations were etched with $37 \%$ phosphoric acid for $30 \mathrm{~s}$, and the etchant was thoroughly rinsed for $20 \mathrm{~s}$. The bonding tooth surface was gently air-dried followed by active application of dentin adhesive for $20 \mathrm{~s}$. The adhesive was then gently air-dried from cervical to incisal aspect and light cured for $20 \mathrm{~s}$. Then, dentin composite of A2 shade was applied on to the tooth surface and enamel composite on to the intaglio surface. Then, prefabricated veneers were gently placed without any excessive pressure, aligned with arch and adjacent teeth, and was double checked for symmetry. While holding the veneers in position, the excess composite material was removed and it was smoothly adapted to the componeer with Sable brush. The entire restorative complex consisting of componeer and composite was light-cured from lingual, facial, cervical, and incisal aspect for $40 \mathrm{~s}$, respectively. Interproximal areas were polished with finishing and polishing strips. Flexible aluminum oxide discs were used to adjust the incisal angles. Silicon rubber polishing cups were used for cervical margins [Figure 2].

\section{DISCUSSION}

The different restorative techniques available for anterior teeth anomalies like peg laterals include indirect ceramic crowns and veneers, direct computeraided design computer-aided manufacturing technique (Cerec), direct prefabricated and individualized ceramic veneers (Lumineers, Cerinate), and freehand technique with composite and newly direct composite veneers, especially the componeer. ${ }^{[7,8]}$ The above-mentioned techniques represent changing trends of dental techniques over time and patient's requirements in modern era. Ceramic crowns are predictable and durable strategy for anterior teeth but require an excessive tooth reduction that may affect pulpal and periodontal health. ${ }^{\left[{ }^{[9}\right.}$ All the indirect techniques are time consuming, material intensive, 


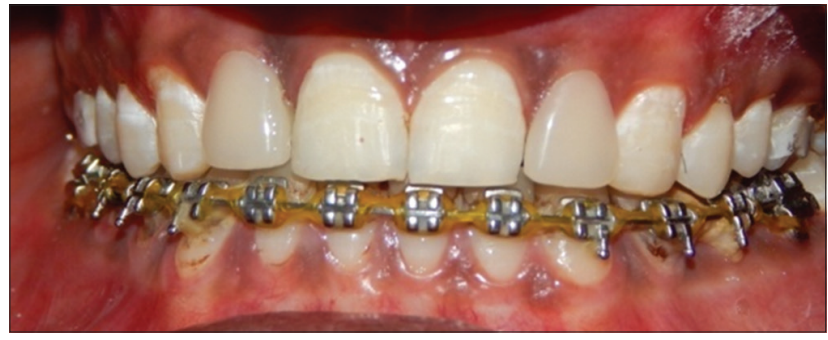

Figure 2: Post-operative frontal view showing entire restorative complex consisting of componeer and composite was

light-cured from all aspects of maxillary lateral incisors

painful, and combined with high costs. Then, chairside veneering with ceramics was introduced, and different direct ceramic systems evolved but they are not feasible in difficult cases. ${ }^{[10]}$ In case of porcelain veneers, limitation is because of sandwich technique and adhesion to enamel or composite is less. The freehand composite technique has limiting factor of homogeneity that leads to surface porosity or discoloration and marginal leakage due to poor adhesion and may get easily chipped off. Componeers, a chairside veneering technique based on composite, was introduced recently with a lot of advantages. It fulfills the criteria of natural beauty with better contouring, minimal invasiveness, ability of individualization, cost-benefit relationship, repair possibility, and technical and dental feasibility ${ }^{[6]}$ Componeers, prefabricated veneers by Coltene, Switzerland, consists of thin composite resin shells $(0.3 \mathrm{~mm}$ cervically and $0.6-1 \mathrm{~mm}$ at the incisal edge). They are fabricated using prepolymerized hybrid composite resin, Synergy D6, Coltene. These veneers are cemented on to the minimally prepared tooth surface with the same hybrid composite from which they are made. The unique microretentive surface of componeer $(2 \mu)$ simplifies the conditioning without any sandblasting and salinization. They form a $100 \%$ copolymerization with bonding material so that they act as a monoblock. The clinical outcome of the componeer depends on the strength of two interfaces: The tooth/resin cement and veneer/resin cement interfaces. A recent bond strength study reported that componeer, the prefabricated veneers, have a high microshear bond strength which is statistically similar to those of etched IPS emax Press. ${ }^{[1]}$ The flexural strength of componeer is between 120 and $160 \mathrm{Mpa}$, and elastic modulus ranges from 8.5 to 12 Gpa.${ }^{[12]}$ Comparing with composite, they have a better marginal adaptation, less polymerization shrinkage, improved wear resistance, color stability, and good homogeneity. ${ }^{[13,14]}$

\section{CONCLUSION}

The most minimally invasive approach for pegshaped laterals is orthodontic treatment, but most of the times, a restorative approach is also needed. Among the various restorative techniques discussed, componeers is the one which fulfils a lot of criteria at the present scenario. They are pre-polymerized enamel shade composite shells, which enables an easier procedure in freehand with composite. They are minimally invasive one with good esthetics and cost-effectiveness. Further studies have to be carried out to understand their mechanical properties and durability in depth.

\section{REFERENCES}

1. Ferro KJ. Glossary of prosthodontic terms. J Prosthet Dent 1999;81:90

2. Bello A, Jarvis RH. A review of aesthetic alternatives for the restoration of anterior teeth. J Prosthet Dent 1997;78:437-40.

3. William R. Contemporary Orthodontics-Proffit. $4^{\text {th }}$ ed. St Louis: Mosby; 2009.

4. Walls AW, Murray JJ, Mc Cabe JF. Composite laminate vemeers: A clinical study. J Oral Rehabil 1998;15:439-54.

5. Dietschi D, Devigus A. Prefabricated composite veneers: Historical perspectives, indications and clinical application. Eur J Esthet Dent 2011;6:178-87.

6. Gomes G, Perdigão J. Prefabricated composite resin veneers-a clinical review. J Esthet Restor Dent 2014;26:302-13.

7. Conrad HJ, Seong WJ, Pesun IJ. Current ceramic materials and systems with clinical recommendations: A systematic review. J Prosthet Dent 2007;98:389-404.

8. Devlin H. Operative Dentistry - A Practical Guide to Recent Innovations. Verlag Berlin: Springer; 2006.

9. Chaturvedi A, Singh A. A reasonable smile with componeers-a case repot. Annals Dent Spec 2015;3:33.

10. Gurel G. Influence of enamel preservation on failure rates of porcelain laminate veneers. Int $J$ Prosthodont 2013;33:31-9.

11. Perdigão J, Sezinando A, Muñoz MA, Luque-Martinez IV, Loguercio AD. Prefabricated veneers - bond strengths and ultramorphological analyses. J Adhes Dent 2014;16:137-46.

12. Borba A, Bona DA, Cecchetti A. Flexural strength and hardness of direct and indirect composites. Braz Oral Res 2009;23:5-10

13. Ferracene JL, Condon JR. Post-cure heat treatment for composite properties and fractographie. Dent Mater 1992;8:290-5.

14. Mandikos MN, McGivney GP, Davis E, Bush PJ, Carter JM. A comparison of the wear resistance and hardness of indirect composite resins. J Prosthet Dent 2001;85:a386-95. 